\title{
Multiple Submission, Duplicate Submission and Duplicate Publication
}

Double or multiple journal submissions are simultaneous submissions of a manuscript to two or more journals at the same time (1-3). If information on that action is not provided to the editor, this phenomenon is called duplicate submission $(3,4)$. Duplicate (or redundant) publication refers to a publication that is nearly identical in content to a previous publication by at least one common author $(4,5)$.

Authors engage in duplicate publication misconduct for several reasons, such as the need to have many publications to obtain an academic degree, promotions or research grants $(4,6)$. We have also observed that authors may attempt this misconduct due to a need for quicker publication, subsequent omission and loss of control of previous submissions (7). Some authors withdraw their manuscript from other journals as soon as it is accepted by one journal. We check and suggest that all editors check for duplications whenever a request for withdrawal is received.

Simultaneous multiple journal submission is a method that has been proposed to reduce the time required for the review and publication processes (2). However, it is not widely accepted, and there are doubts that it would reduce the time required for the publication process $(1,3)$. In addition, multiple journal submission may prevent the improvement of manuscripts based on reviewers' comments because the method could lead journals to compete with each other for quicker evaluation (1). Moreover, multiple journal submission increases the work loads of editors and reviewers (1). The Balkan Medical Journal does not allow multiple submissions.

Duplicate submission is unacceptable behavior, as is duplicate publication. Both duplicate submission and duplicate publication cause editors and reviewers to spend their valuable time and efforts unnecessarily. Authors engaged in these types of misconduct should expect editorial actions to be taken (4-6), including editorial investigation and informing all authors, authors' institutions and other journals about the misconduct. The two COPE guidelines explain the procedures for such editorial actions $(8,9)$. For duplicate publication, the article is retracted and a retraction notice is published by the journal in which the article was most recently published (9). An article was recently retracted from the Balkan Medical Journal due to duplicate publication (10).

When a manuscript is submitted to the Balkan Medical Journal or any other journal, previous meeting presentations (oral or poster), similar reports and any closely related papers (published or under review) should be clearly stated in the cover letter to the editor to prevent possible duplicate publication (5). If the manuscript has been previously submitted or reviewed or is undergoing peer review by another journal, the manuscript must either be rejected or withdrawn, with the approval of the editor, before it is resubmitted to another journal (3). Accordingly, information on previous submissions and review reports may be helpful in reducing the time required to reevaluate the manuscript (11). For that purpose, the Balkan Medical Journal accepts and encourages the authors to send previous review reports and their responses.

After unpleasant experiences, the editorial board and the publisher of the Balkan Medical Journal have decided to check all papers two or three times with plagiarism software (iThenticate) (12): during the review process to detect duplicate submission as well as the plagiarism of portions of the text; before publication on the journal's website, in advance of printing; and/or just before publication in the journal to detect duplicate publication. In addition, reviewers are expected to help editors identify duplicate submissions, as they are expected to closely follow recent publications and meetings and may review the same manuscript for more than one journal during the same time period $(7,13)$.

Authors and co-authors bear the primary responsibility to prevent duplications. If they did not do so at the time of submission, they must openly ask their co-authors about possible duplicate submissions and provide editors with all possible duplicate material as soon as any doubt exists. Additionally, editors and reviewers must take proactive roles in preventing duplications. For example, the duration of the review process should be reduced as much as possible. The Balkan Medical Journal has recently made good progress in reducing the length of the review process. According to the most recent analyses of the journal, the median response time for all submissions is 3 weeks. We have also updated the "Instructions to Authors" with more detailed information and clearer instructions, which are expected to be more useful to authors than the previous version of the instructions.

According to the Editorial Policy of the Balkan Medical Journal, the main aim of the journal is "to publish original articles with high scientific and ethical quality, and also to be a good example of medical publication in the Balkans." The members of the Editorial Board of the Balkan Medical Journal are active professors from various medical specializations, and 
they receive no remuneration for their editorship duty. They carry out this serious job voluntarily and independently, and meet at least once a week for three hours, in addition to many hours spent reviewing papers. The Balkan Medical Journal believe that quality publication will lead to progress of the medical sciences and healthcare in the Balkan countries and worldwide.

\section{Professor Cem UZUN, MD \\ Editor-in-Chief, Balkan Medical Journal \\ Department of Otolaryngology, Trakya University Faculty of Medicine, Edirne, Turkey}

\section{References}

1. Pressman S. Simultaneous multiple journal submissions: The case against. Am J Econ Sociol 1994;53:316-33. [CrossRef]

2. Torgerson DJ, Adamson J, Cockayne S, Dumville J, Petherick E. Submission to multiple journals: a method of reducing time to publication? BMJ 2005;330(7486):305-7. [CrossRef]

3. CSE's white paper on promoting integrity in scientific journal publications. Editorial Policy Committee (2005-2006), Council of Science Editors. http://astro.berkeley.edu/ kalas/ethics/documents/authorship/cse_whitepaper.pdf (access: 01 December 2012).

4. Kaul TK, Grewal A: Duplicate publications or submissions: an ethical misconduct. J Anaesth Clin Pharmacol 2010;26:139-42.

5. ICMJE's uniform requirements for manuscripts submitted to biomedical journals: writing and editing for biomedical publication
(Updated: April 2010). http://www.icmje.org/urm_full.pdf (access: 01 December 2012).

6. Dogra S, Yadav S: Duplicate publication: What an editor can do? Indian J Dermatol Venereol Leprol 2010;76:99-102. [CrossRef]

7. Uzun C, Inan M. [The role of reviewer in prevention of duplication]. In: Yilmaz O, Ed. Refereeing in periodical publications. Periodical publishing in health sciences -2012. Ankara: TUBITAKULAKBIM, 2012:57-60. (in Turkish)

8. What to do if you suspect redundant (duplicate) publication: Suspected redundant publication in a submitted manuscript. The Committee on Publication Ethics (COPE) flowcharts. http:// publicationethics.org/files/u2/01A_Redundant_Submitted.pdf (access: 01 December 2012).

9. What to do if you suspect redundant (duplicate) publication: Suspected redundant publication in a published article. The Committee on Publication Ethics (COPE) flowcharts. http://publicationethics.org/files/u2/01B_Redundant_Published.pdf (access: 01 December 2012).

10. Retraction notice. Balkan Med J 2012;29:460.

11. A short guide to ethical editing for new editors. The Committee on Publication Ethics. http://publicationethics.org/files/short\%20 guide $\% 20$ to $\% 20$ ethical\%20 diting\%20for\%20new\%20 ditors. pdf (access: 10 January 2013).

12. Ozturk L. Plagiarism bros. Ctrl-C and Ctrl-V are under surveillance. Balkan Med J 2011;28:351. [CrossRef]

13. Duplicate submission. Case number: 09-15. COPE cases. The Committee on Publication Ethics (COPE). http://publicationethics. org/case/duplicate-submission-manuscript-\%E2\%80\%98plantand-soil\%E2\%80\%99-plso5942-and-\%E2\%80\%98applied-soilecology\%E2\%80\%99-apsoil-d-0 (access: 01 December 2012) 